\title{
A Head-to-Head Comparison of aripiprazole and risperidone for safety and treating autistic disorders, a randomized double blind clinical trial
}

Running title: comparing aripiprazole and risperidone for treating autism

Ahmad Ghanizadeh, ${ }^{1,2} \mathrm{MD}$, Associate Professor of psychiatry

Ali Akbar Sahraeizadeh, ${ }^{1,2}$ MD

Michael Berk ${ }^{3,4}$

${ }^{1}$ Research Center for Psychiatry and Behavioral Sciences, ${ }^{2}$ Department of Psychiatry, Shiraz University of Medical Sciences, School of Medicine, Hafez Hospital, Shiraz, Iran ${ }^{3}$ Professor of Psychiatry, School of Medicine, Deakin University

${ }^{4}$ Professorial Research Fellow, The Florey Institute of Neuroscience and Mental Health, Orygen Research Centre and the Department of Psychiatry, University of Melbourne

Corresponding author: Ahmad Ghanizadeh, Research Center for Psychiatry and Behavioral Sciences, Department of Psychiatry, Hafez Hospital, Shiraz, Iran.

Telfax: +98-711-627 9319

Email: ghanizad@sina.tums.ac.ir 


\section{Acknowledgment}

This study was the undergraduate thesis of Dr. A.A. Sahraeizadeh. This study was supported by a grant (No: 3135) from Shiraz University of Medical Sciences to Professor Ahmad Ghanizadeh. MB is supported by the Simons Autism Foundation. MB has received Grant/Research Support from the NIH, Cooperative Research Centre, Simons Autism Foundation, Cancer Council of Victoria, Stanley Medical Research Foundation, MBF, NHMRC, Beyond Blue, Rotary Health, Geelong Medical Research Foundation, Bristol Myers Squibb, Eli Lilly, Glaxo SmithKline, Organon, Novartis, Mayne Pharma and Servier, has been a speaker for Astra Zeneca, Bristol Myers Squibb, Eli Lilly, Glaxo SmithKline, Janssen Cilag, Lundbeck, Merck, Pfizer, Sanofi Synthelabo, Servier, Solvay and Wyeth, and served as a consultant to Astra Zeneca, Bristol Myers Squibb, Eli Lilly, Glaxo SmithKline, Janssen Cilag, Lundbeck Merck and Servier, and is a co-inventor of two provisional patents regarding the use of NAC and related compounds for

psychiatric indications, which, while assigned to the Mental Health Research Institute, could lead to personal remuneration upon a commercialization event.

\section{Conflict of interest}

There is no conflict of interest to be declared. 


\title{
A Head-to-Head Comparison of aripiprazole and risperidone for safety and treating autism spectrum disorders, a randomized double blind clinical trial
}

\begin{abstract}
Aripiprazole and risperidone are the only FDA approved medications for treating irritability in autistic disorder, however there are no head-to-head data comparing these agents. This is the first prospective randomized clinical trial comparing the safety and efficacy of these two medications in patients with autism spectrum disorders. Fifty nine children and adolescents with autism spectrum disorders were randomized to receive either aripiprazole or risperidone for two months. The primary outcome measure was change in Aberrant Behavior Checklist (ABC) scores. Adverse events were assessed. Aripiprazole as well as risperidone lowered $\mathrm{ABC}$ scores during two months. The rates of adverse effects were not significantly different between the two groups. The safety and efficacy of aripiprazole (mean dose $5.5 \mathrm{mg} /$ day) and risperidone (mean dose 1.12 $\mathrm{mg} / \mathrm{day}$ ) were comparable. The choice between these two medications should be on the basis of clinical equipoise considering the patient's preference and clinical profile.
\end{abstract}

Keywords: autism, treatment, aripiprazole, risperidone, clinical trial, randomized. 


\section{Introduction}

Autism spectrum disorders are a group of neuropsychiatric disorders characterized by the key symptoms of impairments in social relationships, verbal and non-verbal communications, repetitive behaviors, and restricted behaviors. In contrary to early reports, its prevalence appears to be increasing $(1,2)$. The neurobiology of autism is not clearly known. However, oxidative stress is suggested as a treating target $(3,4)$.

Aripiprazole and risperidone are the only two FDA approved medications for treating irritability in patients with autistm. While both of them are effective, their use in autism is limited due to their limited spectrum of efficacy and their adverse effects (5). However, there is an opinion that the adverse event profile of aripiprazole is more favorable than risperidone (6). Nevertheless, evidence-based data is required to confirm this opinion (6).

While some intervention such as atomoxetine (7) or hyperbaric oxygen therapy failed to show strong clinical efficacy for treating autism (8), risperidone is widely used for treating autism and its utility has been replicated in children with autism (9-11). Risperidone controls disruptive behaviors in some reports, while others suggest that risperidone does not target actual causes of disruptive behaviors (12). However, weight gain is a significant adverse effect of risperidone (13, 14), although its sedative effects tend to reduce after 2 weeks, while its therapeutic effects remain stable for 6 months $(15,16)$.

The most common adverse effects of aripiprazole in children with autism are weight gain (17), vomiting, nasopharyngitis, increased appetite, and insomnia (18) (19). 
It is important to select medications with least adverse effects and potentially higher efficacy. However, the tolerability of these medications in children and adolescents with autism spectrum disorders is not well-studied. In addition, the relative dosage of aripiprazole and risperidone for this indication is unclear.

The current study is a randomized double blind controlled clinical trial comparing the efficacy and safety of aripiprazole and risperidone for treating children with autism spectrum disorders. To the best of authors' knowledge, no study has compared these two medications in a sample of children with autism spectrum disorder.

\section{Methods}

\section{Participants}

Children and adolescents with autism spectrum disorders were recruited from the child psychiatry outpatient clinic affiliated with Shiraz University of Medical Sciences. The children and their parents were interviewed face to face by a child and adolescent psychiatrist (A.G.). The diagnoses were made using DSM-IV-TR-Diagnostic and statistical manual of mental disorders (20) and according to Autism Diagnostic Interview-Revised (ADI-R) (21). In addition, the children had a clinician rating of at least moderate severity of autistic symptoms (Clinical Global Impression Severity score of $\mathrm{C} 4$, range $0-7)$. Children with a history of medically significant or uncontrolled medical conditions, such as hypothyroidism, diabetes or cancer were excluded. Children with a history of drug or alcohol abuse were excluded. Co-morbid psychiatric disorder was not an exclusion criterion. The children could not have received risperidone or aripiprazole 
during at least 2 weeks before entering this trial. In addition, the children could have not received additional behavioral interventions, above the regular educational programming, during this trial. The children were allowed to take concurrent medications except antipsychotics. However, no marked change in dose of concurrent medications was allowed during the trial and during 2 weeks before the trial onset.

The trial protocol and all procedures were approved by the Ethics Committees of Shiraz University of Medical Sciences. The trial was also registered prior to enrolling patients at the Iranian Clinical Trials Registry (http://www.irct.ir) (IRCT201110233930N15). The trial was conducted according to the Declaration of Helsinki and subsequent revisions and approved by the ethics committee. The parents provided written informed consents before participants entered into the trial.

\section{Study design}

Fifty nine children and adolescents with autism spectrum disorders were randomly assigned to one of the two groups of equal size of either risperidone or aripiprazole given twice daily. No stratification considering factors, such as age, gender, diagnoses was conducted. The duration of this trial was two months.

The medication dose was not fixed and could be adjusted according to clinical efficacy and adverse effects. The dose of risperidone was titrated up to $2 \mathrm{mg} /$ day during the first two weeks for children between 10 and $40 \mathrm{~kg}(0.25 \mathrm{mg}$ starting dose with increment in the first 2 weeks). The maximum dose for children under $40 \mathrm{~kg}$ was $2 \mathrm{mg}$, and for those over $40 \mathrm{~kg}$ was up to 3 $\mathrm{mg} /$ day (22). The dose of aripiprazole was titrated up to $10 \mathrm{mg} /$ day over two weeks $(1.25 \mathrm{mg} / \mathrm{day}$ 
starting dose). The maximum dose of aripiprazole for children less than $40 \mathrm{~kg}$ was up to 10 $\mathrm{mg} /$ day and up to $15 \mathrm{mg} /$ day for children more than $40 \mathrm{~kg}$ ) (23).

\section{Outcome}

Behavioral changes were assessed using Aberrant Behavior Checklist (ABC) (24). This 58-items checklist is composed of five subscales, including Irritability and Agitation, Lethargy and Social Withdrawal, Stereotypic Behavior, Hyperactivity and Noncompliance, and Inappropriate Speech. Our primary outcome was the irritability subscale score.

In addition, the Clinical Global Impression-Improvement (CGI-I) scale was used to measure the global severity and changes in core autism symptoms.

Extrapyramidal symptoms and other adverse effects were systematically examined and assessed using a checklist. Moreover, weight, height, and blood pressure were measured.

The children were assessed three times, including at baseline, one month after the onset of intervention, and two months after the onset of intervention (Endpoint) using all of the questionnaires and checklists. Both rater and the patients were blind to treatment assignment. One rater assessed all patients. However, the clinician who administered the medications was not blind to assignment in order to be able to initiate and adjust the dose of medications. About $\underline{7 \text { of }}$ the parents were not blinded to the group assignment because they could correctly guess the group allocation or requested to be not blinded to it. However, it was not related to experience of $\underline{\text { adverse effect. }}$

A. S. was trained by A.G. to use these questionnaires and rate the patients considering direct observation and face-to-face interview. 


\section{Statistical analysis}

SPSS software was used to perform statistical analyses. Considering alpha $=0.05$, Beta $=0.2$, and 5 score difference between the two groups on the subscale of irritability from ABC, the required sample size in each group was estimated to be 15 patients.

Separate repeated measures analyses of variance were performed. The data were compared between the two groups (factor) and the three measurements during the trial were considered as a within-subjects factor (time).

Age was compared between the two groups using t-test. Gender ratio and adverse events rate were compared between the two treatment groups using Chi-square tests and Fisher's exact test, whenever applicable.

In addition, we also performed five separate linear regression analyses to compare the efficacy of the treatments on the five subscale scores of $\mathrm{ABC}$. Age, gender and the baseline score were considered as independent variables and the subscale score of $\mathrm{ABC}$ after two months from the onset of trial was considered as the dependent variable.

A second round of statistical analyses using the intent-to-treat (ITT) imputation method of EM (expectation-maximization) was conducted to handle the missing values.

\section{Results}

Of the 63 children and adolescents initially referred, 59 patients were enrolled in this trial. Three patients withdrew from the trial. Of those enrolled, $64.5 \%$ were diagnosed as having autism, and 
the percentage of who were diagnosed with Asperger disorder, PDD-NOS, and childhood disruptive behavior disorder were $12.9 \%, 16.1 \%$, and $1.6 \%$, respectively. Gender was not associated with group $(\mathrm{X} 2=0.8, \mathrm{df}=1, \mathrm{P}=.3)$. In the aripiprazole group, $4(13.8 \%)$ of the participants were female, and in the risperidone group, $7(23.3 \%)$ patients were female. The age range of the children was between 4 to 18 years old. The mean age of the children in the aripiprazole and risperidone groups was 9.6( $\mathrm{SD}=3.3)$ and 9.5( $\mathrm{SD}=4.6)$ years, respectively. The mean age of the participants was not different between the two groups $(\mathrm{t}=0.06 \mathrm{df}=57, \mathrm{P}=0.9)$.

The mean of weight of the children at baseline was not different between the aripiprazole and risperidone groups [(33.7( $\mathrm{SD}=15.9)$ versus $30.4(\mathrm{SD}=16.6)$, respectively $(\mathrm{t}=0.7, \mathrm{df}=57, \mathrm{P}=0.4)]$. The mean height (in centimeters) of children in the aripiprazole group (133.3(SD=20.5) and risperidone group (127.3( $\mathrm{SD}=24.2)$ was also not statistically different $(\mathrm{t}=1.0, \mathrm{df}=57, \mathrm{P}=0.3)$.

The flow chart of recruitment, allocation and final analyzed sample in this trial is displayed in Figure 1. Two patients in the aripiprazole group and one patient in risperidone group did not receive medication. Three patients in each group dropped out from this trial. The reasons for discontinuation in the aripiprazole group were; hospitalized due to the severity of symptoms $(n=1)$, exacerbation of epilepsy $(n=1)$, and severe sedation after taking medication $(n=1)$. The reasons for discontinuation in the risperidone group were: lack of efficacy $(n=1)$, declined to return $(n=1)$, and severe agitation and crying after taking medication $(n=1)$.

The mean baseline ABC irritability subscale $(\mathrm{t}=1.9, \mathrm{df}=57, \mathrm{P}=0.06)$, hyperactivity and noncompliance $(\mathrm{t}=0.2, \mathrm{df}=57, \mathrm{P}=0.8)$, stereotypic behavior $(\mathrm{t}=0.1, \mathrm{df}=57, \mathrm{P}=0.8)$, lethargy and Social Withdrawal $(\mathrm{t}=0.9, \mathrm{df}=57, \mathrm{P}=0.3)$, and Inappropriate speech scores $(\mathrm{t}=0.2, \mathrm{df}=57$, 
$\mathrm{P}=0.8$ ) were not different between the two groups. However, there was a non-significant statistical trend for higher baseline Irritability subscale scores in the aripiprazole group at baseline.

Figures 2 to 6 show that both risperidone and aripiprazole decreased all the ABC subscales scores significantly during the trial within groups. However, the effect of these two medications between groups on autism symptoms measured by $\mathrm{ABC}$ subscales was not significantly different.

Repeated measures ANOVA showed that both aripiprazole and risperidone decreased the irritability subscale score during the trial $(\mathrm{F} 1,49=153.8, \mathrm{P}<0.001)$. The interactive effect of time and group (timexgroup) was statistically different $(\mathrm{F} 1,49=2.7, \mathrm{P}<0.04)$. However, there was no statistically significant between group difference $(\mathrm{F} 1,49=3.7, \mathrm{P}=0.06)$ (Table 1$)$. The pattern of changes for irritability scores was similar in the two groups.

Linear regression analysis also showed that group was not significantly associated with ABC Irritability and Agitation subscale score at endpoint assessment $(\mathrm{P}=0.8)$. In addition, group was not associated any of the other ABC subscales scores at endpoint assessment [Hyperactivity and Noncompliance $(\mathrm{p}=0.3)$, Lethargy and Social Withdrawal $(\mathrm{p}=0.8)$, Stereotypic Behavior $(\mathrm{p}=0.2)$, Inappropriate Speech $(\mathrm{p}=0.3)]$.

Adverse effect rates are displayed in Table 2. The most common adverse effects were increased appetite, increased drooling, and drowsiness. Only two patients withdrew from the trial because of adverse effects. One patient experienced exacerbated epilepsy in aripiprazole group and dropped out of the trial. One patient dropped out because of severe crying and agitation after taking risperidone. 
Regarding weight, repeated measures ANOVA showed that the interaction of time and group (interactive effect of Time $\mathrm{X}$ Group) was not statistically significant $(\mathrm{F} 1,49=0.50, \mathrm{P}=0.5)$. The effect of group was also non-significant $(\mathrm{F} 1,49=0.06, \mathrm{P}=0.8)$.

On the Clinical Global Impression-Severity (CGI-S) and CGI Improvement (CGI-I) scales, the rate of "severely ill" and "among most extremely ill patient" categories at baseline in the aripiprazole (41.4\% and $30.0 \%$ respectively) and risperidone (58.6\% and $70.0 \%$ respectively) was not different between the two groups $(\mathrm{X} 2=0.8, \mathrm{df}=1, \mathrm{P}=0.3)$.

Clinical Global Impression (CGI) scores at endpoint showed that the rate of improvement was not different between the two groups $(\mathrm{X} 2=3.1, \mathrm{df}=3, \mathrm{P}=0.3)$. Nine patients in aripiprazole group and 5 patients in risperidone group were "Much Improved". The number of children in the "minimally improved" category in the aripiprazole group and risperidone group was 7 and 12 , respectively. Five patients in aripiprazole group and eight patients in risperidone group were in the "No change" category. Finally, three patients in the aripiprazole group and 2 patients in the risperidone group were in the "Minimally Worse" category.

A second round of statistical analysis using ITT analyses showed a similar pattern to the first round of statistical analysis. In other words, there were no differences between the two groups regarding autistic symptoms as measured by the $\mathrm{ABC}$ subscales.

\section{Discussion}


This head-to-head study aimed to compare the safety and efficacy of aripiprazole and risperidone in children with autism spectrum disorders. The main outcome was decrease in the irritability and agitaion subscale of the Aberrant Behavior Checklist.

The results of this study showed that aripiprazole and risperidone decrease all the ABC subscales scores, including Irritability and Agitation, Lethargy and Social Withdrawal, Stereotypic Behavior, Hyperactivity and Noncompliance, and Inappropriate Speech. In addition, other than the Irritability and Agitation score, the interaction of treatment group and time was not different for any of Lethargy and Social Withdrawal, Stereotypic Behavior, Hyperactivity and Noncompliance, and Inappropriate Speech. This implies that the pattern of response of irritability and agitation to these medications during this trial was significantly different. In other words, after first month, the decrease in the irritability and agitation subscale score in the aripiprazole group was greater than in the risperidone group. This suggests that aripiprazole decreased irritability and agitation scores earlier than risperidone. Nevertheless, repeated ANOVA measures showed no difference between the two groups. It can be interpreted that there were no significant differences between the two groups on irritability and agitation scores after two months. Linear regression analysis showed that there was no association between groups and Irritability and Agitation score after one month $(\mathrm{P}=0.1)$. Therefore, the differences reported by ANOVA are in all likelihood due to baseline differences in Irritability and Agitation score rather than the effect of medication.

In addition, both aripiprazole and risperidone improve Lethargy and Social Withdrawal, Stereotypic Behavior, Hyperactivity and Noncompliance, and Inappropriate Speech in autism 
spectrum disorders. There were no differences in the pattern of response to these medications on these subscales.

It needs to be noted that 9 of 27 subjects were rated as "much improved" on the CGI-I in the aripiprazole group and 5 of 29 subjects were rated as much improved in the risperidone group. Sample sizes for categorical measures need to be larger than for continuous measures, and the study may have been underpowered for this analysis and a type 2 error is possible.

No significant difference was observed between the two groups regarding the rate of adverse effects. Moreover, the rate of discontinuation of medications because of adverse effects was limited to one patient in each group. Increased appetite was the most common adverse effect, being present in $34.5 \%$ of the aripiprazole group and $40 \%$ of the risperidone group. Drooling was also common, with more than $31 \%$ of the children in aripiprazole group and $40 \%$ of the risperidone group reporting this adverse event. The rate of enuresis in the aripiprazole and risperidone groups was zero and 2, respectively.

The mean dose of aripiprazole and risperidone during the first month of trial was 4.6(SD=1.9) and $1.09(\mathrm{SD}=0.9)$, respectively. The mean dose during the second month of trial in aripiprazole and risperidone groups was $5.5(\mathrm{SD}=2.2)$ and $1.12(\mathrm{SD}=0.9)$, respectively. Therefore, it was observed that $4.6 \mathrm{mg}$ /day of aripiprazole decreases the $\mathrm{ABC}$ subscales scores as much as $1.1 \mathrm{mg} /$ day of risperidone in children and adolescents with autistic disorders. Nevertheless, lack of differences does not mean that these two medications are equivalent. Furthermore, the results of this study cannot be generalized to other doses of these two medications in terms of expected efficacy and adverse effects. Further studies with larger sample sizes are recommended. 
In conclusion, current evidences suggest that aripiprazole and risperidone are broadly equivalent choices for treating irritability in children with autism. The choice between these two medications should be on the basis of clinical equipoise considering the patient's preference and clinical profile.

\section{$\underline{\text { Summary }}$}

This randomized clinical trial compares the safety and efficacy of aripiprazole and risperidone for treating irritability in patients with autism spectrum disorders. Fifty nine children and adolescents with autism spectrum disorders were randomized to receive either aripiprazole or risperidone for two months. The primary outcome measure was change in Aberrant Behavior Checklist (ABC) scores.

The means of age, weight, and height of the children at baseline was not different between the two groups. The rates of adverse effects were not significantly different between the two groups. Three patients in each group dropped out from this trial. Only two patients withdrew from the trial because of adverse effects. One patient experienced exacerbated epilepsy in aripiprazole group and dropped out of the trial. One patient dropped out because of severe crying and agitation after taking risperidone. The most common adverse effects in the aripiprazole and risperidone groups were increased appetite (34.5\% versus $40.0 \%)$, increased drooling $(31.0 \%$ versus $40.0 \%)$, and drowsiness $(20.7 \%$ versus $16.7 \%$, respectively). Only two patients withdrew from the trial because of adverse effects.

Aripiprazole as well as risperidone lowered ABC scores during two months. Irritability score decreased from $26.2(4.1)$ to $14.6(5.5)$ in the aripiprazole group during this trial. The score in the 
risperidone group decreased from 21.5(7.4) to 12.5(5.4). The safety and efficacy of aripiprazole (mean dose $5.5 \mathrm{mg} / \mathrm{day}$ ) and risperidone (mean dose $1.12 \mathrm{mg} / \mathrm{day}$ ) were comparable. The choice between these two medications should be on the basis of clinical equipoise considering the patient's preference and clinical profile. 
Figure 1. Flow chart for the clinical trial of aripiprazole versus risperidone

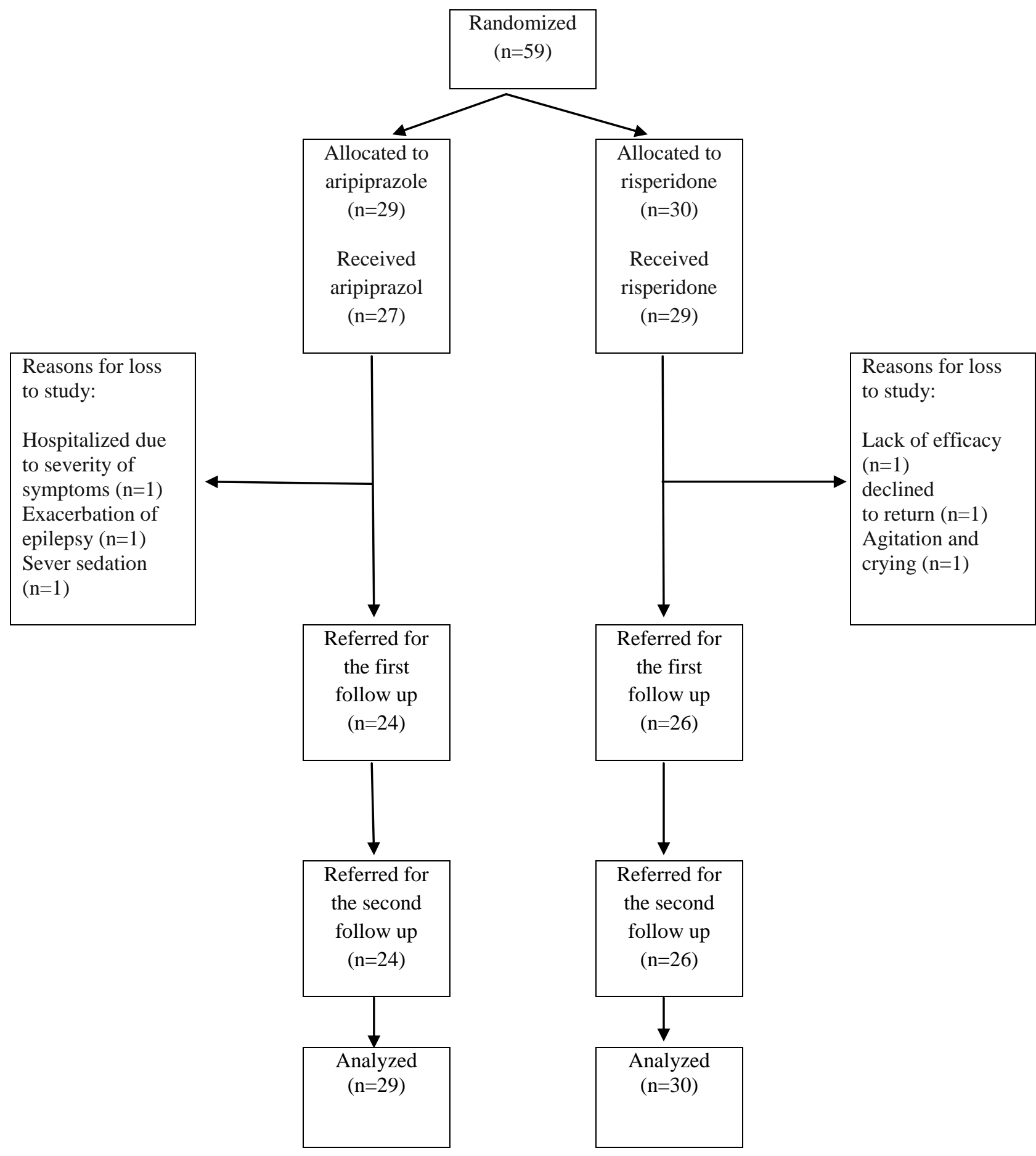


Figure 2. Comparison of irritability subscale scores between the two groups during the trial.

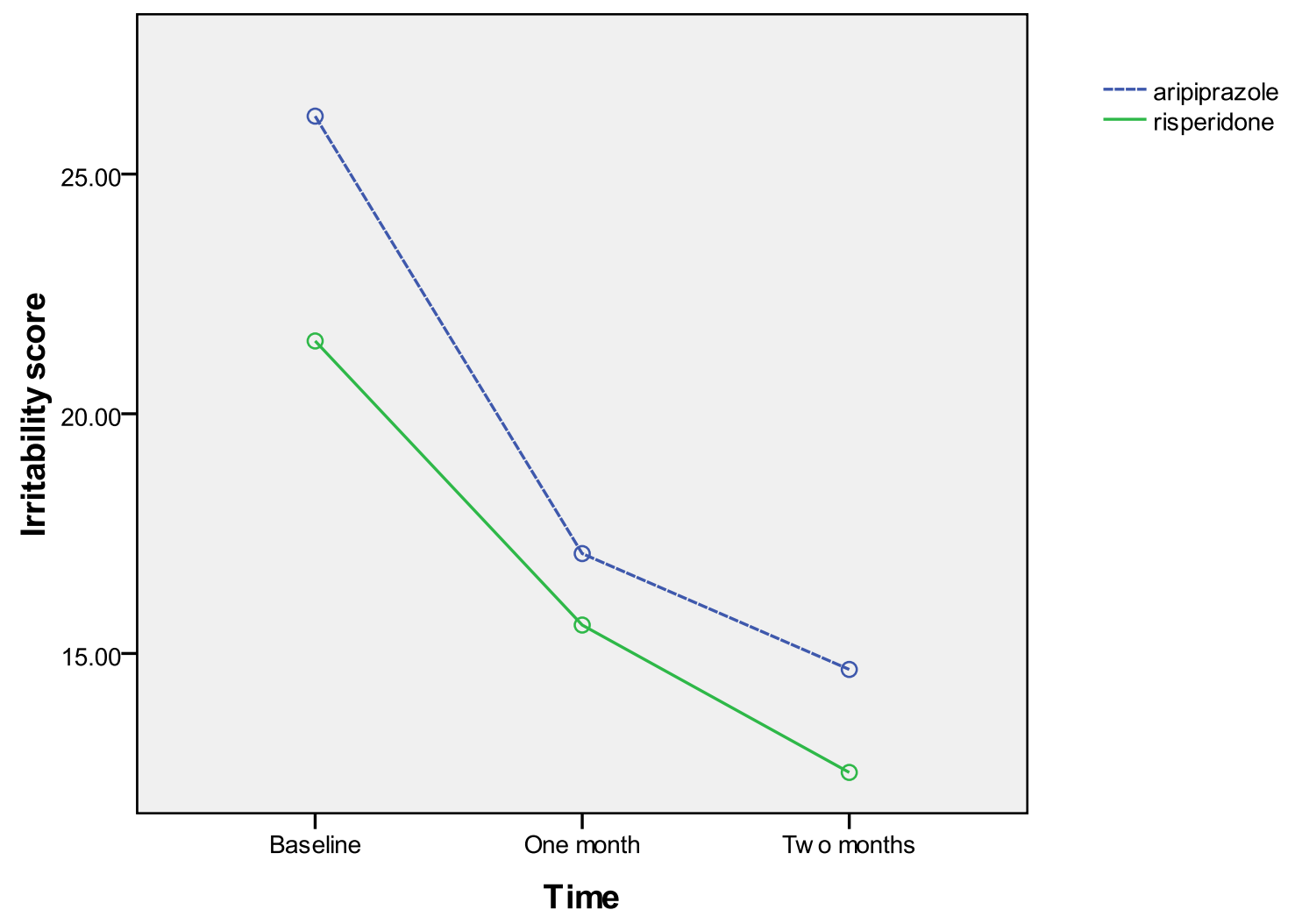


Figure 3. Comparison of hyperactivity and noncompliance subscale scores between the two groups during the trial.

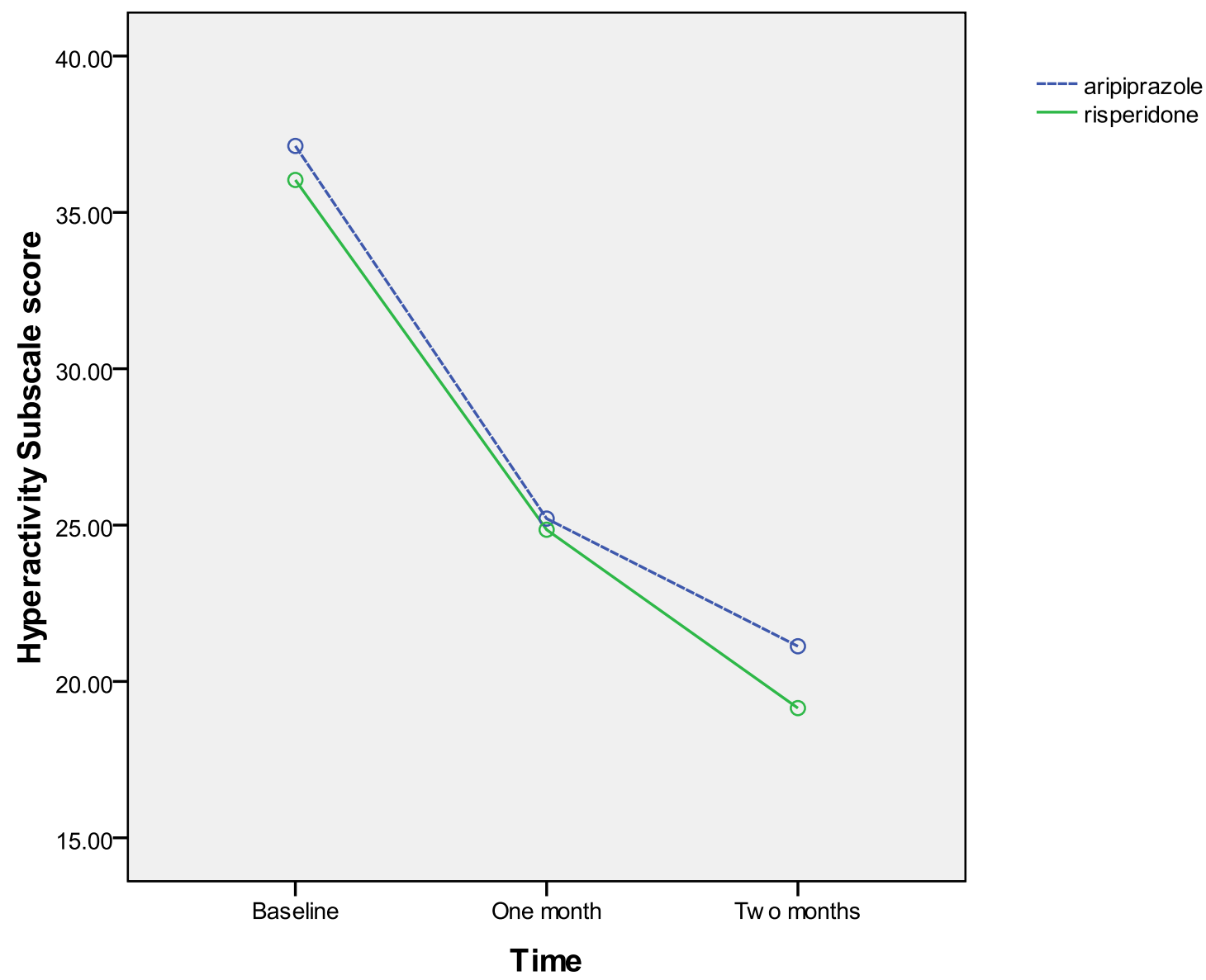


Figure 4. Comparison of stereotypic behavior subscale scores between the two groups during the trial.

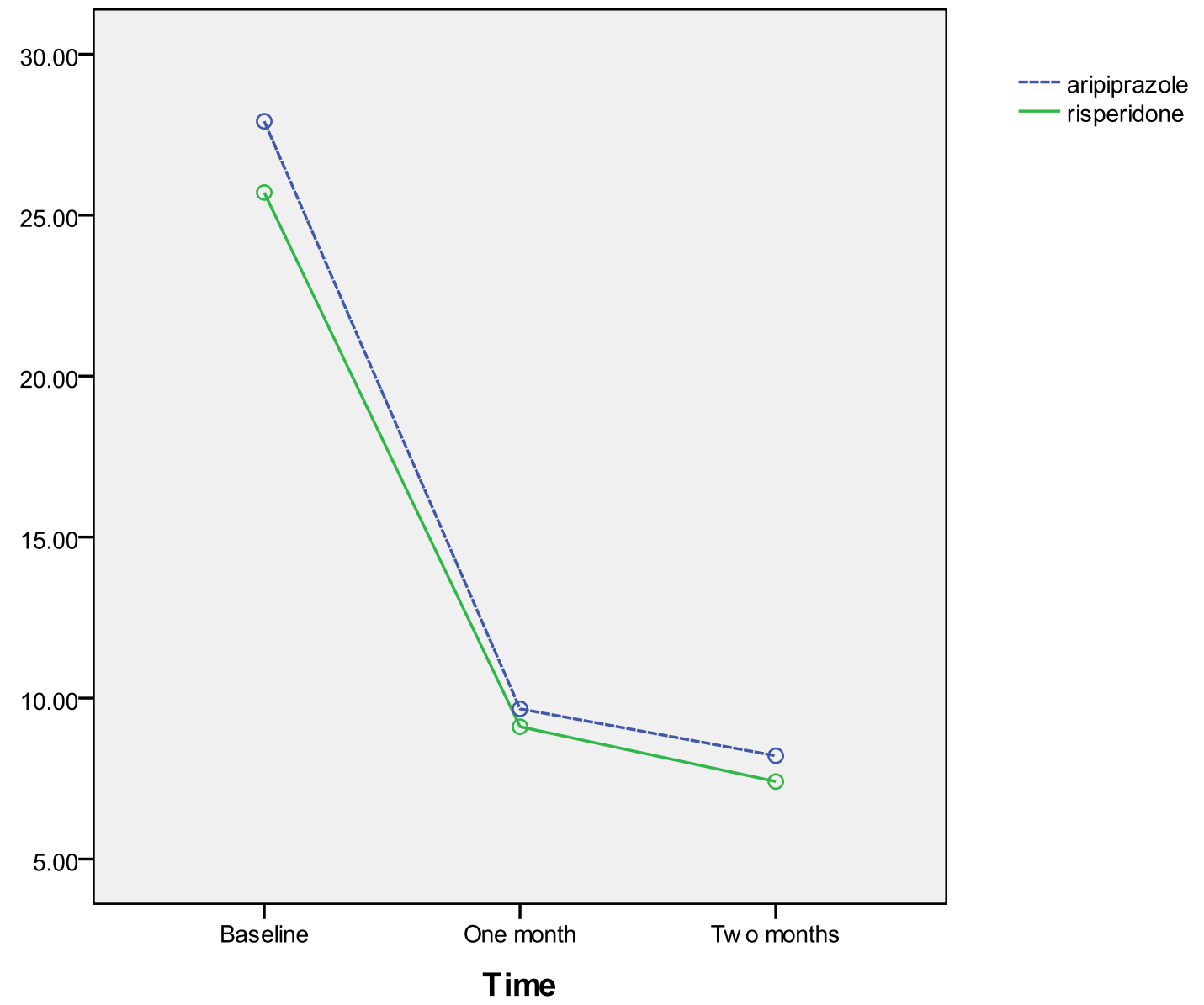


Figure 5. Comparison of lethargy and Social Withdrawal subscale scores between the two groups during the trial.

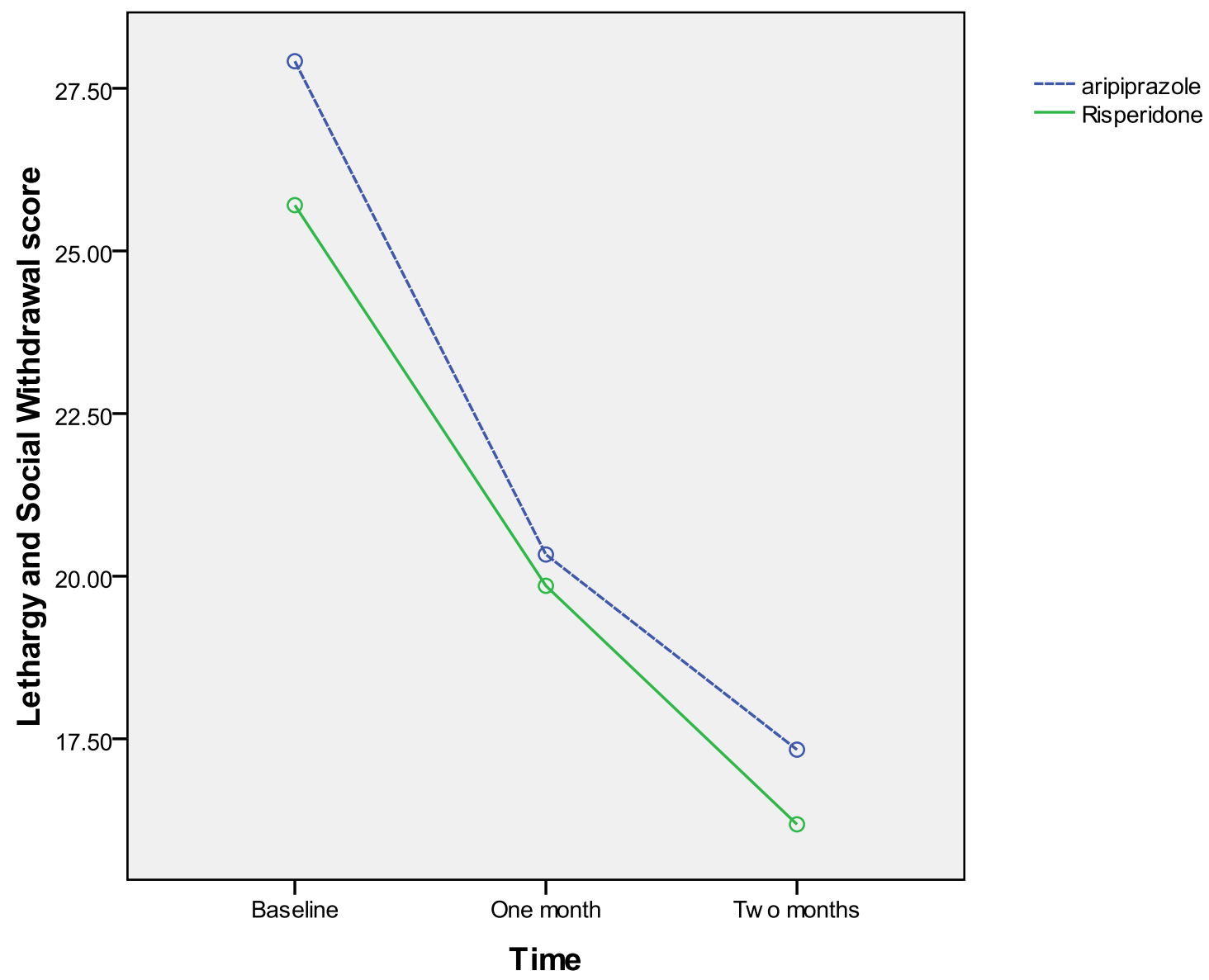


Figure 6. Comparison of Inappropriate speech subscale scores between the two groups during the trial.

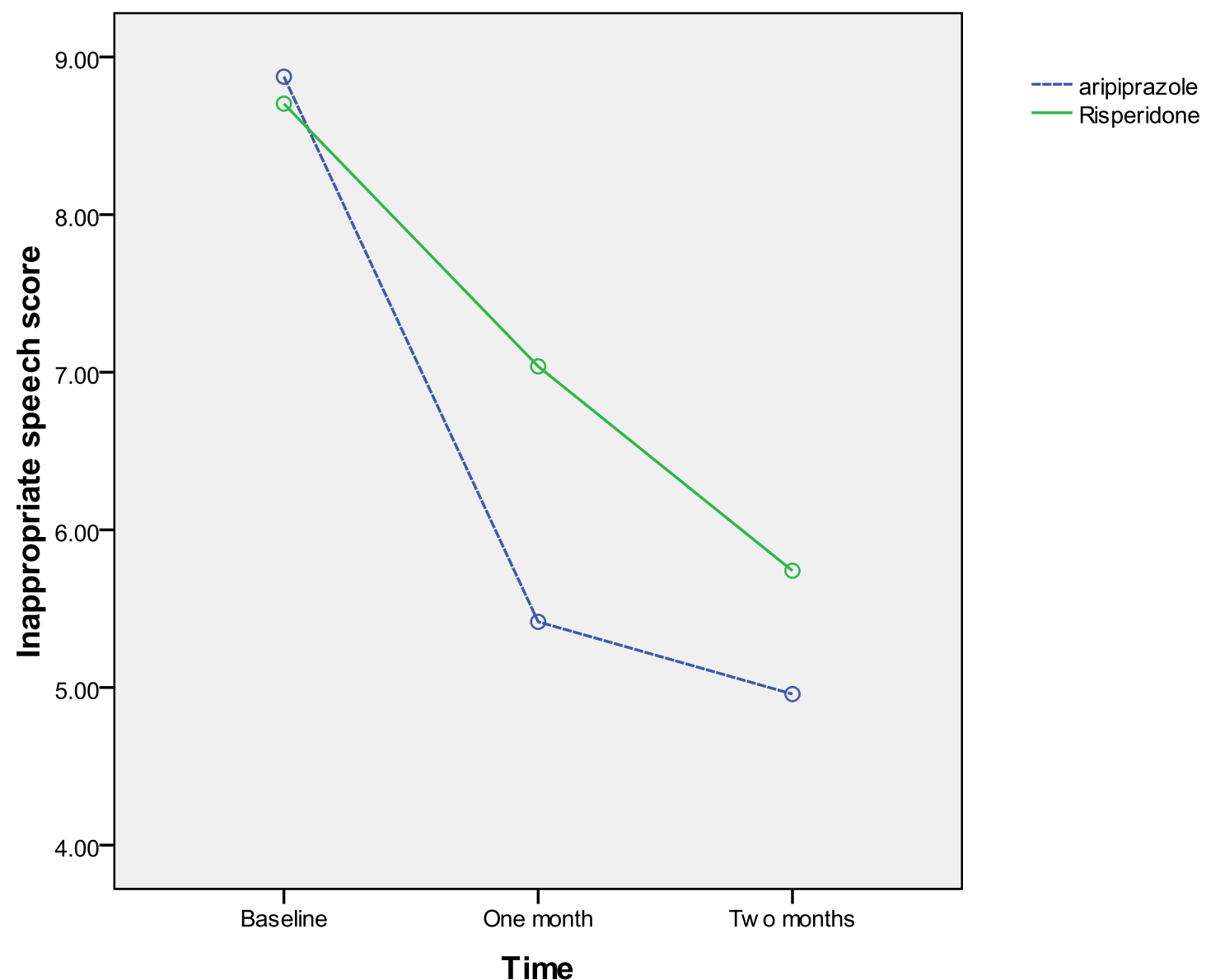


Table 1. Mean and standard deviation of $A B C$ subscales score in the groups during the trial.

\begin{tabular}{|c|c|c|c|c|c|}
\hline Subscale & Group & Baseline & One month & $\begin{array}{c}\text { Two } \\
\text { months }\end{array}$ & Significance \\
\hline \multirow[t]{2}{*}{ Irritability } & aripiprazole & $26.2(4.1)$ & $17(5.4)$ & $14.6(5.5)$ & \multirow[t]{2}{*}{$F 1,49=0.4, P=0.5$} \\
\hline & risperidone & $21.5(7.4)$ & $15.5(5.50$ & $12.5(5.4)$ & \\
\hline \multirow[t]{2}{*}{ Hyperactivity } & aripiprazole & 37.1(7.) & $25.2(8.7)$ & $21.1(9.0)$ & \multirow[t]{2}{*}{$F 1,49=3.7, P=0.06$} \\
\hline & risperidone & $36.0(6.2)$ & $24.8(6.3)$ & $19.1(6.1)$ & \\
\hline \multirow[t]{2}{*}{ Lethargy } & aripiprazole & $27.5(8.4)$ & $20.3(7.6)$ & $17.3(7.4)$ & \multirow[t]{2}{*}{$F 1,49=0.3, P=0.5$} \\
\hline & risperidone & $25.3(8.9)$ & $19.8(7.3)$ & $16.1(6.9)$ & \\
\hline \multirow[t]{2}{*}{ Stereotypy } & aripiprazole & $13.6(5.7)$ & $9.6(5.2)$ & $8.2(5.0)$ & \multirow[t]{2}{*}{$F 1,49=0.2, P=0.6$} \\
\hline & risperidone & 13.2(4.2) & $9.1(3.90$ & 7.4(3.9) & \\
\hline \multirow[t]{2}{*}{ Speech } & aripiprazole & $8.6(3.1)$ & $5.4(2.4)$ & $4.9(2.3)$ & \multirow[t]{2}{*}{$F 1,49=0.8, P=0.3$} \\
\hline & risperidone & $8.9(3.6)$ & $7.0(3.1)$ & $5.7(3.1)$ & \\
\hline
\end{tabular}


Table 3. Rate of adverse effects by group.

\begin{tabular}{|c|c|c|c|c|c|}
\hline \multirow[t]{2}{*}{ Adverse effect } & \multicolumn{2}{|c|}{ Aripiprazole } & \multicolumn{2}{|c|}{ Risperidone } & \multirow[b]{2}{*}{ Significance } \\
\hline & Number & Percent & Number & Percent & \\
\hline Increased appetite & 10 & 34.5 & 12 & 40.0 & 0.7 \\
\hline Drooling & 9 & 31.0 & 12 & 40.0 & 0.5 \\
\hline Day drowsiness & 6 & 20.7 & 5 & 16.7 & 0.7 \\
\hline Decreased Appetite & 6 & 20.7 & 4 & 13.3 & 0.5 \\
\hline Fatigue & 4 & 13.8 & 4 & 13.3 & 1.0 \\
\hline constipation & 4 & 13.8 & 2 & 3.7 & 0.4 \\
\hline Slowness & 4 & 13.8 & 4 & 6.7 & 0.4 \\
\hline Tremor & 3 & 10.3 & 2 & 6.7 & 0.6 \\
\hline dystonia & 3 & 10.3 & 1 & 3.3 & 0.3 \\
\hline Itches & 3 & 10.3 & 0 & - & 0.1 \\
\hline Abdominal pain & 3 & 10.3 & 1 & 3.3 & 0.3 \\
\hline Nervousness & 2 & 6.9 & 1 & 3.3 & 0.6 \\
\hline Dry mouth & 2 & 6.9 & 0 & - & 0.2 \\
\hline Tachycardia & 2 & 6.9 & 1 & 3.3 & 0.6 \\
\hline Restlessness & 1 & 3.4 & 2 & 6.7 & 1.0 \\
\hline Dyskinesia & 1 & 3.4 & 2 & 6.7 & 1.0 \\
\hline Dizziness & 1 & 3.4 & 3 & 10.0 & 0.6 \\
\hline Skin rash & 1 & 3.4 & 1 & 3.3 & 1.0 \\
\hline Walking problem & 1 & 3.4 & 1 & 3.3 & 1.0 \\
\hline Diarrhea & 1 & 3.4 & 0 & - & 0.4 \\
\hline Nausea & 1 & 3.4 & 2 & 6.7 & 1.0 \\
\hline Vomiting & 1 & 3.4 & 1 & 3.3 & 1.0 \\
\hline Insomnia & 1 & 3.4 & 0 & & $0 . .4$ \\
\hline Swallowing difficulty & 0 & - & 0 & & - \\
\hline Blurred vision & 0 & & 0 & - & \\
\hline Seizure & 0 & - & 1 & 3.3 & 1 \\
\hline Bradycardia & 0 & & 0 & & \\
\hline Diurnal enuresis & 0 & - & 2 & 6.7 & 0.4 \\
\hline Depression & 0 & & 1 & 3.4 & 1.0 \\
\hline
\end{tabular}




\section{References}

1. Elsabbagh M, Divan G, Koh YJ, Kim YS, Kauchali S, Marcin C, et al. Global prevalence of autism and other pervasive developmental disorders. Autism Res. 2012;5(3):160-79.

2. Fombonne E. Estimated prevalence of autism spectrum conditions in Cambridgeshire is over 1\%. Evid Based Ment Health. 2012;13(1):32.

3. Ghanizadeh A, Berk M, Farrashbandi H, Alavi Shoushtari A, Villagonzalo KA. Targeting the mitochondrial electron transport chain in autism, a systematic review and synthesis of a novel therapeutic approach. Mitochondrion. 2012.

4. Ghanizadeh A, Akhondzadeh S, Hormozi M, Makarem A, Abotorabi-Zarchi M, Firoozabadi A. Glutathione-related factors and oxidative stress in autism, a review. Current medicinal chemistry. 2012;19(23):4000-5.

5. McPheeters ML, Warren Z, Sathe N, Bruzek JL, Krishnaswami S, Jerome RN, et al. A systematic review of medical treatments for children with autism spectrum disorders. Pediatrics. 2011;127(5):e1312-21.

6. Farmer CA, Aman MG. Aripiprazole for the treatment of irritability associated with autism. Expert Opin Pharmacother. 2011;12(4):635-40.

7. Ghanizadeh A. Atomoxetine for Treating ADHD Symptoms in Autism: A Systematic Review. Journal of attention disorders. 2012.

8. Ghanizadeh A. Hyperbaric oxygen therapy for treatment of children with autism: a systematic review of randomized trials. Medical gas research. 2012;2:13. 
9. Hasanzadeh E, Mohammadi MR, Ghanizadeh A, Rezazadeh SA, Tabrizi M, Rezaei F, et al. A Double-Blind Placebo Controlled Trial of Ginkgo biloba Added to Risperidone in Patients with Autistic Disorders. Child Psychiatry Hum Dev. 2012.

10. Akhondzadeh S, Fallah J, Mohammadi MR, Imani R, Mohammadi M, Salehi B, et al. Double-blind placebo-controlled trial of pentoxifylline added to risperidone: effects on aberrant behavior in children with autism. Progress in neuro-psychopharmacology \& biological psychiatry. 2010;34(1):32-6.

11. Rezaei V, Mohammadi MR, Ghanizadeh A, Sahraian A, Tabrizi M, Rezazadeh SA, et al. Double-blind, placebo-controlled trial of risperidone plus topiramate in children with autistic disorder. Prog Neuropsychopharmacol Biol Psychiatry. 2011;34(7):1269-72.

12. McKinney C, Renk K. Atypical antipsychotic medications in the management of disruptive behaviors in children: safety guidelines and recommendations. Clin Psychol Rev. 2011;31(3):465-71.

13. Maayan L, Correll CU. Weight gain and metabolic risks associated with antipsychotic medications in children and adolescents. J Child Adolesc Psychopharmacol. 2011;21(6):517-35.

14. Jesner OS, Aref-Adib M, Coren E. Risperidone for autism spectrum disorder. Cochrane Database Syst Rev. 2007(1):CD005040.

15. Scott LJ, Dhillon S. Risperidone: a review of its use in the treatment of irritability associated with autistic disorder in children and adolescents. Paediatr Drugs. 2007;9(5):343-54. 16. Aman MG, Arnold LE, McDougle CJ, Vitiello B, Scahill L, Davies M, et al. Acute and longterm safety and tolerability of risperidone in children with autism. J Child Adolesc Psychopharmacol. 2005;15(6):869-84. 
17. Curran MP. Aripiprazole: in the treatment of irritability associated with autistic disorder in pediatric patients. Paediatr Drugs. 2011;13(3):197-204.

18. Marcus RN, Owen R, Manos G, Mankoski R, Kamen L, McQuade RD, et al. Aripiprazole in the treatment of irritability in pediatric patients (aged 6-17 years) with autistic disorder: results from a 52-week, open-label study. J Child Adolesc Psychopharmacol. 2011;21(3):229-36.

19. Robb AS, Andersson C, Bellocchio EE, Manos G, Rojas-Fernandez C, Mathew S, et al. Safety and tolerability of aripiprazole in the treatment of irritability associated with autistic disorder in pediatric subjects (6-17 years old):results from a pooled analysis of 2 studies. Prim Care Companion CNS Disord. 2011;13(1).

20. American Psychiatric Association. Diagnostic and statistical manual of mental disorders. Washington: American Psychiatric Association; 2000.

21. Lord C, Rutter M, Le Couteur A. Autism Diagnostic Interview-Revised: a revised version of a diagnostic interview for caregivers of individuals with possible pervasive developmental disorders. J Autism Dev Disord. 1994;24(5):659-85.

22. Asadabadi M, Mohammadi MR, Ghanizadeh A, Modabbernia A, Ashrafi M, Hassanzadeh E, et al. Celecoxib as adjunctive treatment to risperidone in children with autistic disorder: a randomized, double-blind, placebo-controlled trial. Psychopharmacology (Berl). 2012.

23. Varni JW, Handen BL, Corey-Lisle PK, Guo Z, Manos G, Ammerman DK, et al. Effect of aripiprazole 2 to $15 \mathrm{mg} / \mathrm{d}$ on health-related quality of life in the treatment of irritability associated with autistic disorder in children: a post hoc analysis of two controlled trials. Clin Ther. 2012;34(4):980-92. 
24. Aman MG, Singh NN, Stewart AW, Field CJ. The aberrant behavior checklist: a behavior rating scale for the assessment of treatment effects. Am J Ment Defic. 1985;89(5):485-91. 